Article

\title{
Thermal Behavior of Coal Used in Rotary Kiln and Its Combustion Intensification
}

\author{
Qiang Zhong ${ }^{\mathbb{D}}$, Jian Zhang, Yongbin Yang *, Qian Li, Bin $\mathrm{Xu}$ * and Tao Jiang \\ School of Minerals Processing and Bioengineering, Central South University, Changsha 410083, China; \\ zhongqiang2008csu@163.com (Q.Z.); 15707492684@163.com (J.Z.); csuliqian@126.com (Q.L.); \\ jiangtao@csu.edu.cn (T.J.) \\ * Correspondence: ybyangcsu@126.com (Y.Y.); xuandy_16@126.com (B.X.); Tel.: +86-731-8883-0547 (Y.Y \& B.X.)
}

Received: 7 April 2018; Accepted: 20 April 2018; Published: 25 April 2018

Abstract: Pyrolysis and combustion behaviors of three coals (A, B, and C coals) were investigated and their combustion kinetics were calculated by the Freeman-Carroll method to obtain quantitative insight into their combustion behaviors. Moreover, the effects of coal size, air flow, oxygen content, and heating rate on coal combustion behaviors were analyzed. Results showed that the three coals have a similar trend of pyrolysis that occurs at about $670 \mathrm{~K}$ and this process continuously proceeds along with their combustion. Combustion characteristics and kinetic parameters can be applied to analyze coal combustion behaviors. Three coals having combustion characteristics of suitable ignition temperature $(745-761 \mathrm{~K}), \mathrm{DTG}_{\max }(14.20-15.72 \% / \mathrm{min})$, and burnout time $(7.45-8.10 \mathrm{~min})$ were analyzed in a rotary kiln. Combustion kinetic parameters provide quantitative insights into coal combustion behavior. The suitable particle size for coal combustion in a kiln is that the content of less than $74 \mu \mathrm{m}$ is $60 \%$ to $80 \%$. Low activation energy and reaction order make coal, especially C coal, have a simple combustion mechanism, great reactivity, be easily ignited, and a low peak temperature in the combustion state. Oxygen-enrichment and high heating rates enhance coal combustion, increasing combustion intensity and peak value, thus shortening burnout time.

Keywords: thermal behavior; coal; rotary kiln; thermogravimetric analysis; combustion intensification

\section{Introduction}

Coal as a traditional fossil fuel is widely used in metallurgical production, such as iron and steel production. Iron ore oxide pellets, as an important raw material of iron, are produced by grate-rotary kilns and supplied to blast furnaces for iron making in China. Rotary kilns mainly use coal as an energy source to complete the preheating and roasting of green pellets. Coal consumption in rotary kilns is enormous and emits massive amounts of pollution gas into the atmosphere because 700 million tons of steel is produced every year in China, leading to serious energy consumption and environmental pollution [1-4]. Therefore, it is urgent for people to optimize coal combustion and improve coal-use efficiency.

At present, mathematical models have been designed to forecast heat transfer and sintering temperatures in rotary kilns [5-7]. However, the results predicted by mathematical models are not accurate enough because coal combustion in a kiln is very complex. The research of mathematical models should be further development. Thermal behavior of fuel has been widely studied by thermogravimetric analysis (TGA), which is an extensive and effective research method for studying thermal behavior [8-12]. Thermal characteristics of ignition temperature, burnout temperature, maximum combustion rate, and combustion kinetic parameters can be acquired to quantitatively analyze the thermal process of fuel [13-15]. However, the thermal reaction process of coal in a rotary kiln has not been clearly understood. Since the thermal behavior of coal in kiln is unclear, 
there is a lack of proper regulation for its combustion, resulting high coal consumption and great environmental pollution.

In our previous studies, TGA was used to reveal coal thermal behavior in forming coal briquettes. Coals employed in a rotary kiln were studied to analyze their pyrolysis and combustion processes, and their interaction on co-combustion was also studied. Moreover, the intensification of air flow and oxygen on coal combustion behavior has been researched by isothermal TGA [16-19]. Based on these works, three coals (A, B, and C coals) used in a rotary kiln were adopted to study their thermal behaviors, and their combustion characteristic parameters were obtained. Kinetic parameters were calculated to give an assessment of the three coals. Moreover, the effects of coal size, air flow, oxygen content, and heating rate on their combustion behaviors were investigated. With these research results, the coals' thermal behaviors in a rotary kiln were understood clearly. Combustion characteristic parameters and kinetic parameters were used to quantitatively assess coal in production, and the intensified methods such as coal size, the oxygen-enrichment and heat rates were acquired.

\section{Experimental}

\subsection{Materials and Equipment}

The three coals (A, B, and C coals) used in the experiment were supplied by a Chinese pellet plant. In order to represent the characteristics of the raw coal as much as possible, careful sampling was performed. Coal samples were broken and screened to a size below $74 \mu \mathrm{m}$.

Proximate and ultimate analysis results and the heating value of the three coals are show in Table 1 . The three coals have the similar basic properties, especially A coal and B coal. Among these three coals, $\mathrm{C}$ coal has the highest heating value $(7832 \mathrm{Kcal} / \mathrm{kg})$ because of its high fixed carbon content. The sulfur content of C coal is only $0.34 \%$, while that of A coal and B coal are $1.07 \%$ and $1.06 \%$, respectively. In general, the coals used for rotary kiln pellet production has properties of low sulfur content (lower than 1.07\%), high fixed carbon content (higher than $75.41 \%$ ), appropriate volatile matter (about 13\%), and high heating value (higher than $7536 \mathrm{Kcal} / \mathrm{kg}$ ).

Table 1. Proximate analysis, ultimate analysis, and heating values of coal samples.

\begin{tabular}{|c|c|c|c|c|c|c|c|c|c|}
\hline \multirow[b]{2}{*}{ Samples } & \multicolumn{3}{|c|}{ Proximate Analyses (wt. \%, d) } & \multicolumn{5}{|c|}{ Ultimate Analyses (wt. \%, d) } & \multirow{2}{*}{$\begin{array}{l}\text { Qnet.d } \\
\text { (Kcal/kg) }\end{array}$} \\
\hline & $\begin{array}{l}\text { Volatile } \\
\text { Matter }\end{array}$ & $\begin{array}{c}\text { Fixed } \\
\text { Carbon }\end{array}$ & Ash & $\mathrm{C}$ & $\mathbf{H}$ & $\mathbf{N}$ & $\mathbf{O}$ & $\mathbf{S}$ & \\
\hline A coal & 12.90 & 76.47 & 10.63 & 79.79 & 3.53 & 1.17 & 1.90 & 1.07 & 7794 \\
\hline B coal & 13.15 & 75.41 & 11.44 & 78.54 & 3.47 & 1.12 & 2.34 & 1.06 & 7536 \\
\hline C coal & 12.66 & 79.05 & 8.29 & 80.78 & 3.67 & 1.28 & 3.57 & 0.34 & 7832 \\
\hline
\end{tabular}

\subsection{Methods}

Proximate analyses of the coal samples were performed according to standard practices (GB/T212-2008). For the ultimate analyses of the coal samples, the LECO Truspec CHN-Sultimate analysis instrument (Leco Corporation, St. Joseph, MI, USA) was applied to analyze the C, H, N, $\mathrm{O}$, and $\mathrm{S}$ content of the three coals. The heating value was measured with an adiabatic oxygen bomb calorimeter.

A differential thermogravimetric analyzer STA449C (precision of temperature measurement $\pm 1 \mathrm{~K}$, microbalance sensitivity $0.1 \mu \mathrm{g}$ ) (NETZSCH, Selb, Bavaria, Germany) was employed to study thermal behavior. Coal samples of about $8 \mathrm{mg}$ were used in each test. For common combustion tests, the heating rate and flow rate were respectively fixed at $20 \mathrm{~K} / \mathrm{min}$ and $100 \mathrm{~mL} / \mathrm{min}$, and the temperature range was from $293 \mathrm{~K}$ to $1273 \mathrm{~K}$. The flow rate was changed in air flow tests $(100 \mathrm{~mL} / \mathrm{min}, 200 \mathrm{~mL} / \mathrm{min}$, and $300 \mathrm{~mL} / \mathrm{min}$ ), and different heating rates of $10 \mathrm{~K} / \mathrm{min}, 20 \mathrm{~K} / \mathrm{min}$, and $30 \mathrm{~K} / \mathrm{min}$ were used 
in the heating rate tests. The thermal degradation kinetics of the three coals was calculated by the Freeman-Carroll method. Combustion kinetics of coal can be revealed by Equation (1) [20,21].

$$
\frac{\mathrm{d} \alpha}{\mathrm{dt}}=\mathrm{kf}(\alpha)
$$

In Equation (2), $\alpha$ is the conversion degree of combustible material. In Equation (3), the absolute temperature and rate constant are described by T and $\mathrm{k}$. Moreover, $\mathrm{f}(\alpha)$ is the reaction model function, usually revealed as $f(\alpha)=(1-\alpha) n$, where $n$ is the order of reaction. The initial weight, the weight at any time ( $t$ ), and the final weight are respectively described by $W_{0}, W_{f}$, and $W_{t}$. $R$ and $A$ are the universal gas constant $(8.314 \mathrm{~J} / \mathrm{mol})$ and the Arrhenius parameter, respectively. The apparent activation energy is represented by $\mathrm{E}_{\alpha}$.

$$
\begin{gathered}
\alpha=\frac{W_{0}-W_{t}}{W_{0}-W_{f}} \\
k=\operatorname{Aexp}^{-E_{\alpha} / R T}
\end{gathered}
$$

Furthermore, Equation (1) can be described as follows:

$$
\frac{\mathrm{d} \alpha}{\mathrm{dt}}=\operatorname{Aexp}^{-\mathrm{E}_{\alpha} / \mathrm{RT}}(1-\alpha)^{\mathrm{n}}=\mathrm{A}(1-\alpha)^{\mathrm{n}} \exp ^{-\mathrm{E}_{\alpha} / \mathrm{RT}}
$$

Equation (4) can be expressed as the different formation by taking logarithm

$$
\ln \left(\frac{\mathrm{d} \alpha}{\mathrm{dt}}\right)=\ln \mathrm{A}+\mathrm{n} \ln (1-\alpha)-\frac{\mathrm{E}_{\alpha}}{\mathrm{RT}}
$$

If the apparent activation energy is hardly affected by the small change in temperature, Equation (5) can be expressed as follows:

$$
\frac{\triangle \ln \left(\frac{\mathrm{d} \alpha}{\mathrm{dt}}\right)}{\triangle \ln (1-\alpha)}=\mathrm{n}-\frac{\mathrm{E}_{\alpha}}{\mathrm{R}} \times \frac{\Delta \mathrm{T}^{-1}}{\triangle \ln (1-\alpha)}
$$

By plotting $\Delta \ln (\mathrm{d} \alpha / \mathrm{dt}) / \Delta \ln (1-\alpha)$ against $\Delta \mathrm{T}^{-1} / \Delta \ln (1-\alpha)$, the intercept and straight slope of the regression line can be calculated to describe the parameters $E_{\alpha}$ and $n$, respectively. Then, the Arrhenius parameter (A) can also been calculated from Equation (5).

\section{Results and Discussion}

\subsection{Thermal Behavior}

\subsubsection{Pyrolysis Behavior}

Pyrolysis tests of the three coals are shown in Figure 1 and their characteristic parameters of pyrolysis are acquired in Table 2. The temperature value rate is described as the peak temperature when the rate of weight loss reaches the maximum, and the rate at peak temperature is expressed as the maximum rate $\left(\mathrm{DTG}_{\max }\right)$.

As seen in Figure 1 and Table 2, the three coals have similar weight-loss trends and two separate phases in the coal-pyrolysis process. The first pyrolysis stage is the evaporation stage of water, and the weight loss of coal has little effect on its thermal behavior. Next, is the devolatilization stage. For the A coal, this ranges from $650 \mathrm{~K}$ to $1150 \mathrm{~K}$, with a peak of $831 \mathrm{~K}$ and its $\mathrm{DTG}_{\max }$ being $0.84 \% / \mathrm{min}$. The B coal ranges from $680 \mathrm{~K}$ to $1160 \mathrm{~K}$, with a peak of $798 \mathrm{~K}$ and its $\mathrm{DTG}_{\max }$ being $1.27 \% / \mathrm{min}$. C coal ranges from $670 \mathrm{~K}$ to $1150 \mathrm{~K}$, with a peak of $806 \mathrm{~K}$ and its $\mathrm{DTG}_{\max }$ being $1.02 \% / \mathrm{min}$ [22-24]. Simply put, the pyrolysis of the three coals occurs at about $670 \mathrm{~K}$ and this process continuously proceeds along 
with their combustion. Moreover, weight loss in the pyrolysis process comes close to the volatile matter content of coal, indicating that the pyrolysis process is mainly about the volatilization of volatile matter.

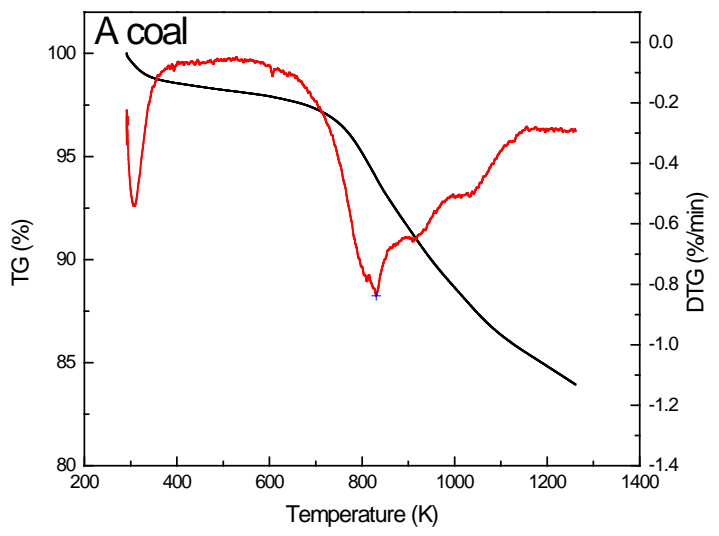

(a)

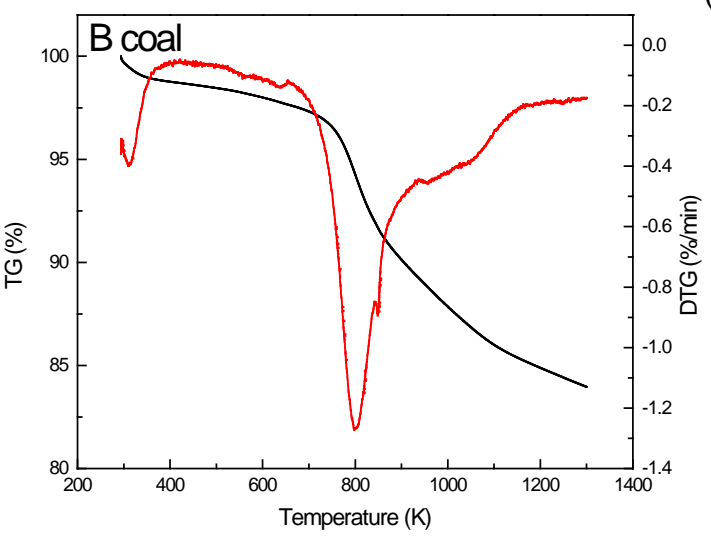

(b)

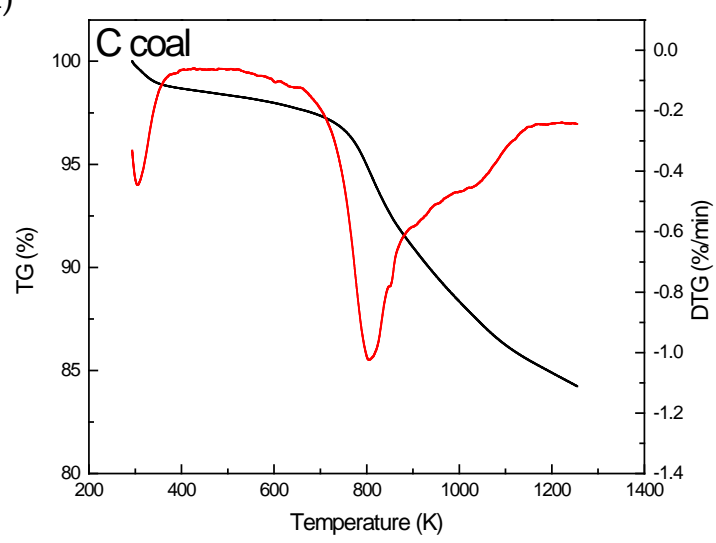

(c)

Figure 1. Pyrolysis behaviors of A coal (a), B coal (b) and C coal (c).

Table 2. Characteristic parameters of pyrolysis behaviors.

\begin{tabular}{ccccc}
\hline \multirow{2}{*}{ Sample } & \multicolumn{2}{c}{ 1st Peak } & \multicolumn{2}{c}{ 2nd Peak } \\
\cline { 2 - 5 } & Temperature (K) & DTG $_{\max }(\% / \mathbf{m i n})$ & Temperature (K) & DTG $_{\max }$ (\%/min) \\
\hline A coal & 307 & 0.54 & 831 & 0.84 \\
B coal & 311 & 0.40 & 798 & 1.27 \\
C coal & 306 & 0.45 & 806 & 1.02 \\
\hline
\end{tabular}

\subsubsection{Combustion Behavior}

Combustion characteristics obtained from the TGA can be used to estimate the combustion efficiency of different coals in a rotary kiln. Combustion behaviors of A, B, and C coals are shown in Figure 2. All three coals show only one peak from their DTG profiles. Combined with the results of the approximate analysis, the main reaction of the three coals' combustion is the combustion of their fixed carbon that greatly contributes to quality loss. The basic trends of the three coals are similar, while they also show many differences in the details. Combustion parameters typically include the ignition temperature, peak temperature, maximum burn rate, and burnout time obtained from thermographs. The ignition temperature is a sudden drop in the DTG profile. Burnout time is the time required for coal to burn from ignition to burnout. The combustion parameters clearly display the combustion characteristic of the three coals, as shown in Figure 2. C coal, with a $745 \mathrm{~K}$ ignition temperature, is the most easily ignited coal, while B coal has the highest ignition temperature $(761 \mathrm{~K})$. Meanwhile, $\mathrm{C}$ coal 
has the lowest peak temperature $(815 \mathrm{~K})$ and the longest burnout time $(8.10 \mathrm{~min})$, indicating that $\mathrm{C}$ coal will ignite at low temperatures and keep combusting for a long time [25]. A coal-burning iron oxidation rotary kiln provides heat to ensure that the temperatures in the kiln head and kiln are not lower than $1523 \mathrm{~K}$. The kiln heat provided by coal combustion should preheat the pellets to ensure that the temperature of the chain grate does not fall below $1223 \mathrm{~K}$ [26]. On this basis, coal with a lower ignition temperature and a longer burn-up time is required during the rotary kiln process. Therefore, $\mathrm{C}$ coal is a kind of high quality coal for a rotary kiln. It not only ensures the high temperature of the rotary kiln and chain grate, but it also saves energy and reduces environmental pollution.

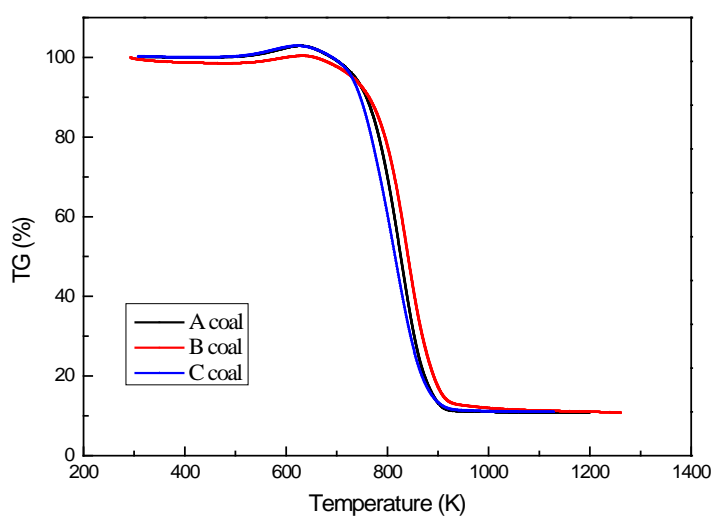

(a)

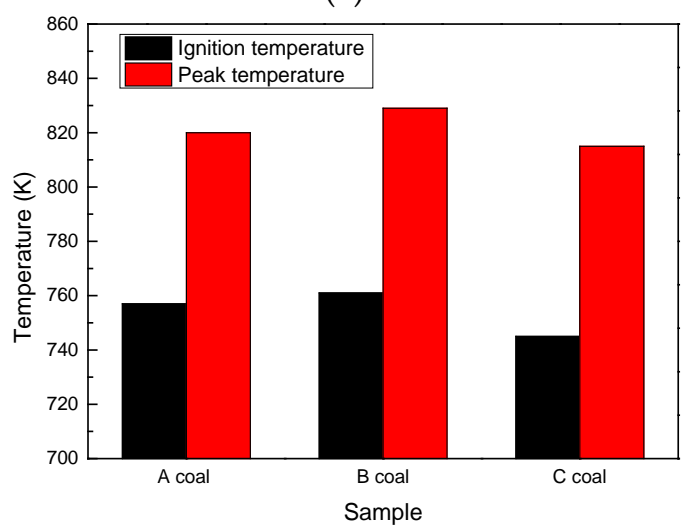

(c)

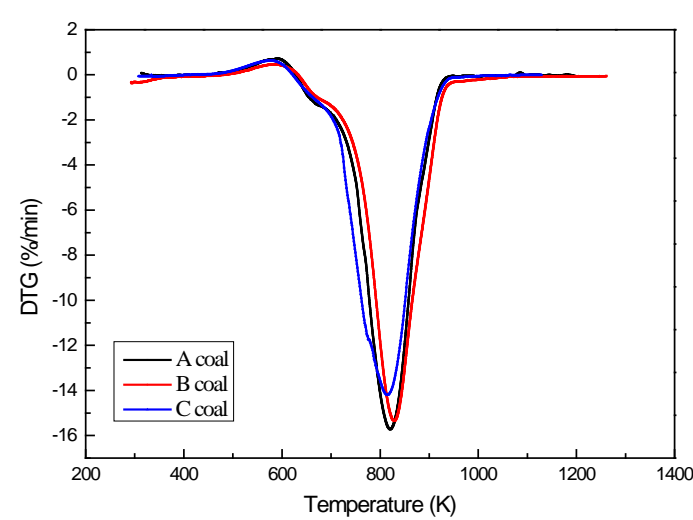

(b)

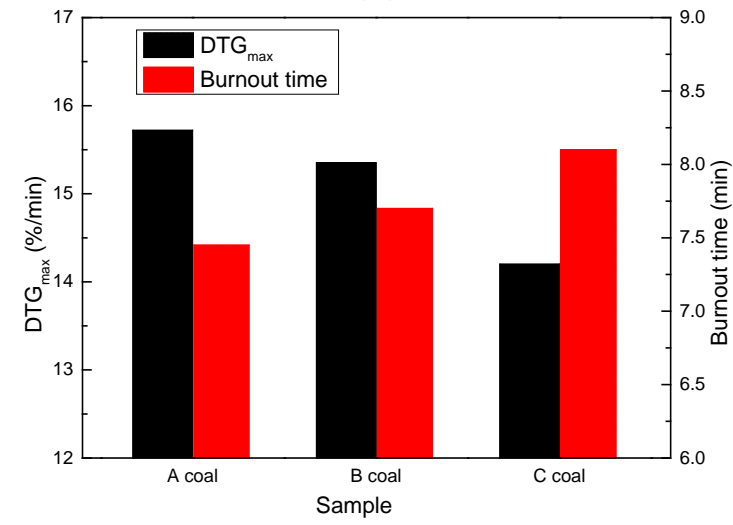

(d)

Figure 2. Combustion behaviors of A coal, B coal, and C coal: (a) TG profile; (b) DTG profile; (c) and (d) Coal combustion characteristics.

In addition, while A and B coals are worse than C coal in combustion characteristic, they can also be applied in pellet production. Therefore, the type of coal used in rotary kilns has the combustion characteristics of 745-761 K for ignition temperature, 815-829 K for peak temperature, $14.20-15.72 \% / \mathrm{min}$ for $\mathrm{DTG}_{\max }$, and 7.45-8.10 min for burnout time.

\subsubsection{Combustion Kinetics}

Three kinds of coal kinetic parameters were obtained using Freeman-Carroll method. Activation energy $\left(E_{\alpha}\right)$ is a quantitative measurement of the energy threshold formed by the combustion product, the reaction sequence $(n)$ is a sign of the combustion reaction mechanism, and the frequency factor (A) produces a frequency measurement of the molecular collision energy response. Higher activation energy $\left(E_{\alpha}\right)$ and reaction sequence $(n)$ indicate greater thermal stability during combustion and more complex combustion conditions [27].

Using the Freeman-Carroll method, the TG and DTG data of the three coals were analyzed. The combustion kinetics characteristics are shown in Figure 3. It shows the reaction of the kinetic 
parameters $\mathrm{E}_{\alpha}$ (slope) and $\mathrm{n}$ ( $y$-axis intercept) generated by the installed straight-line figure. These kinetic parameters and the corresponding correlation factor $R^{2}$ are listed in Table 3 . The results reveal that the value of $\mathrm{R}$ is very high, meaning linear regression is reasonable and the calculation result is reliable. $\mathrm{C}$ coal has the lowest $\mathrm{E}_{\alpha}(109.54 \mathrm{KJ} / \mathrm{mol})$ and $\mathrm{A}\left(4.24 \times 10^{6}\right)$, which implies bad thermal stability and simple combustion mechanisms occurring in the combustion state. Bad thermal stability and simple combustion mechanisms of $\mathrm{C}$ coal show that it has a great reactivity, is easily ignited, and has a low peak temperature, which is consistent with its combustion behavior (Table 3). B coal has the highest $\mathrm{E}_{\alpha}$, reaction order $(\mathrm{n})$ and $\mathrm{A}\left(135.92 \mathrm{KJ} / \mathrm{mol}, 1.16\right.$ and $\left.1.06 \times 10^{8}\right)$, indicating great thermal stability and complex combustion mechanisms occurring in the combustion state. This result is also consistent with its combustion behavior. Thus, the coal used in rotary kilns has a low activation energy and reaction order.
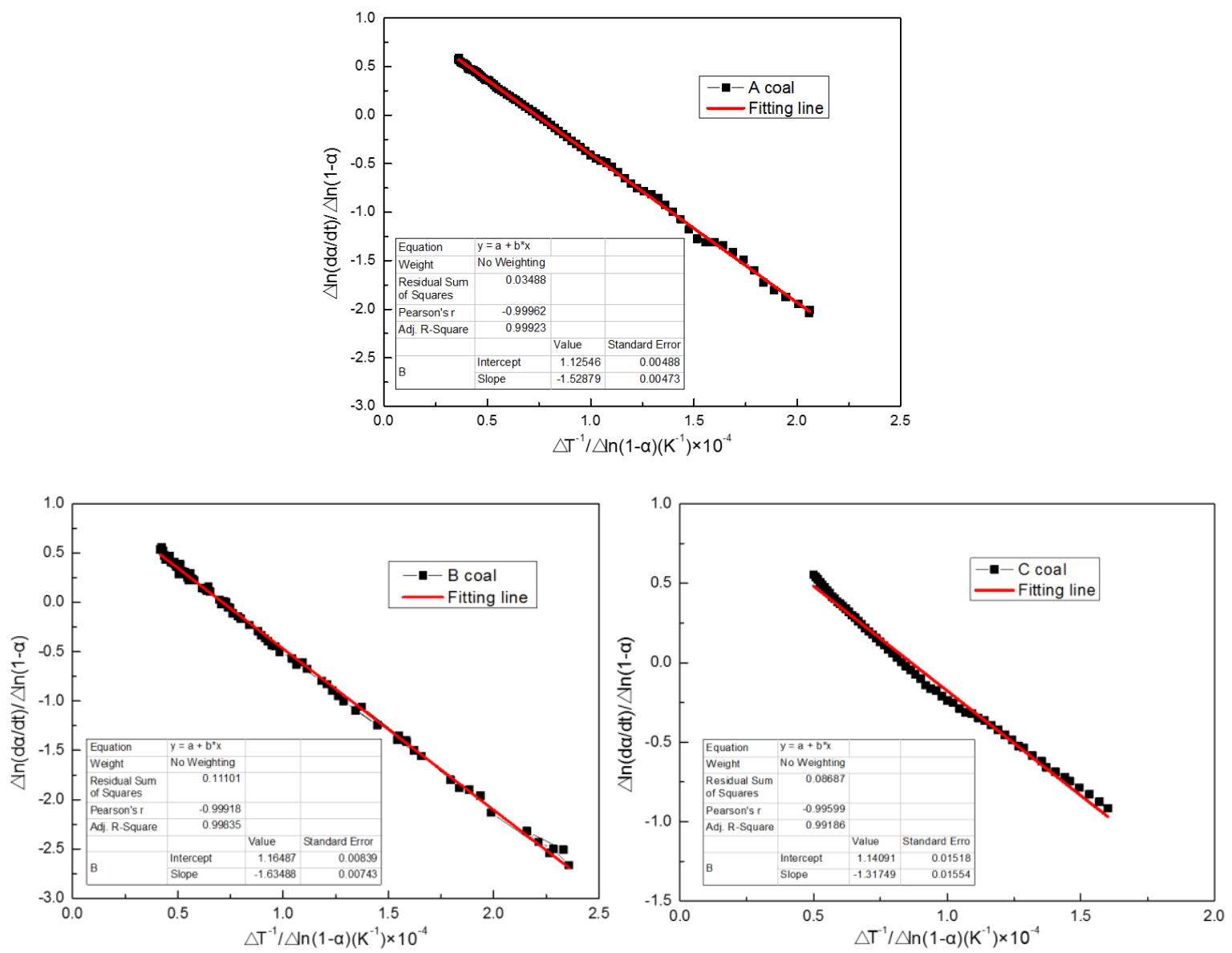

Figure 3. Combustion kinetics profiles of A coal, B coal, and C coal.

Table 3. Kinetic parameters calculated by Freeman-Carroll method.

\begin{tabular}{ccccc}
\hline Sample & $\mathbf{E}_{\boldsymbol{\alpha}}, \mathbf{K J} / \mathbf{m o l}$ & $\mathbf{n}$ & $\mathbf{A}, \mathbf{m i n}^{-\mathbf{1}}$ & $\boldsymbol{R}^{\mathbf{2}}$ \\
\hline A coal & 127.10 & 1.12 & $4.72 \times 10^{7}$ & 0.99923 \\
B coal & 135.92 & 1.16 & $1.06 \times 10^{8}$ & 0.99835 \\
C coal & 109.54 & 1.14 & $4.24 \times 10^{6}$ & 0.99186 \\
\hline
\end{tabular}




\subsection{Combustion Intensification}

\subsubsection{Effect of Coal Size}

Combustion behaviors of A coal with different sizes are shown in Figure 4. Coal size has a great effect on coal combustion. Coal is difficult to ignite and its combustion intensity is weak when its size is too thick $(40 \%-74 \mu \mathrm{m})$. Coal can be ignited at normal ignition temperatures when its $-74 \mu \mathrm{m}$ content is increased to $60 \%$. Further, combustion intensity is enhanced with an increase of $-74 \mu \mathrm{m}$ content. $\mathrm{DTG}_{\max }$ is increased from $14.20 \% / \mathrm{min}$ to $15.46 \% / \mathrm{min}$ and burnout time is shortened from $8.15 \mathrm{~min}$ to $7.40 \mathrm{~min}$ when $-74 \mu \mathrm{m}$ content increases from $60 \%$ to $80 \%$. When continuously increasing the $-74 \mu \mathrm{m}$ content to $100 \%$, combustion has no obvious change, meaning the coal can burn sufficiently when its $-74 \mu \mathrm{m}$ content is $80 \%$. Coal does not need to be ground to $100 \%-74 \mu \mathrm{m}$ content, which would increase energy consumption and costs. Therefore, the suitable size for coal combustion is about $80 \%$ $-74 \mu \mathrm{m}$ content that makes coal combust sufficiently.

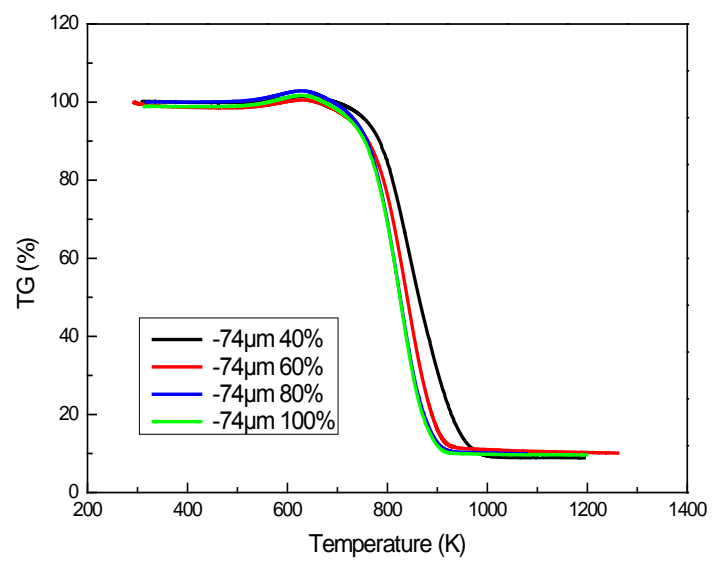

(a)

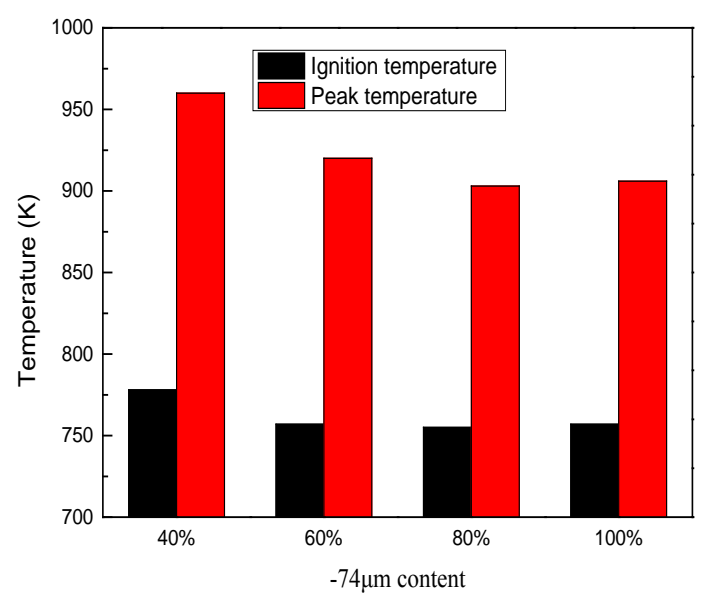

(c)

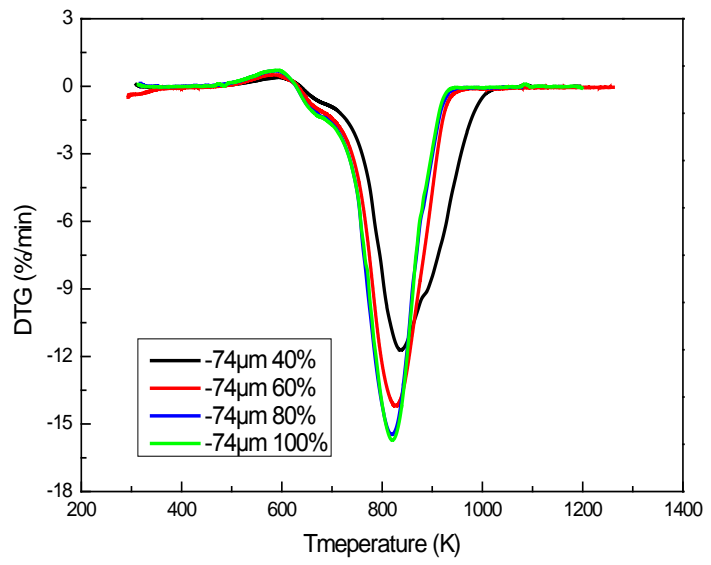

(b)

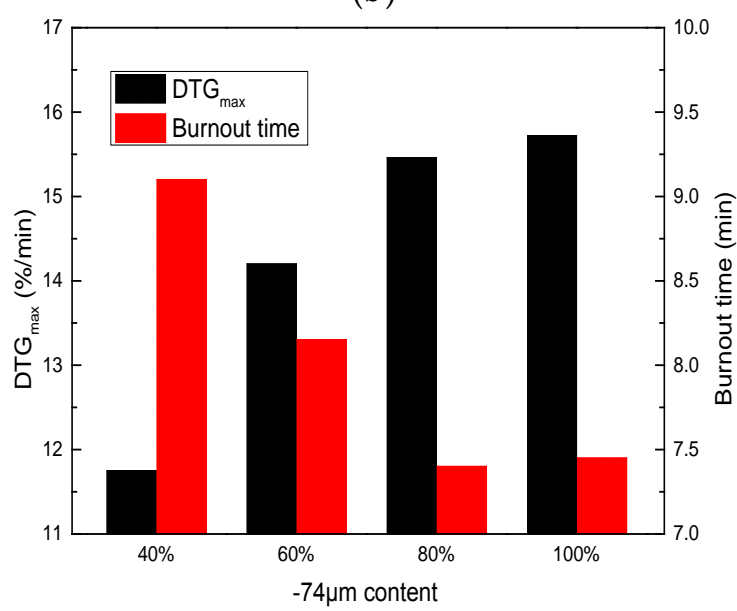

(d)

Figure 4. Effect of size on coal combustion: (a) TG profile; (b) DTG profile; (c) and (d) Coal combustion characteristics.

\subsubsection{Effect of Air Flow}

The effect of air flow on combustion behavior of A coal is shown in Figure 5. Air flow has some effects on coal combustion. Namely, the combustion peak is transferred to a lower temperature, the combustion intensity is enhanced, and the combustion peak value is also raised when air flow increased. With air flow increased from 50 to $200 \mathrm{~mL} / \mathrm{min}$, the peak temperature is depressed from $834 \mathrm{~K}$ to $817 \mathrm{~K}$, the DTG $\mathrm{Dax}_{\max }$ is increased from $14.63 \% / \mathrm{min}$ to $16.48 \% / \mathrm{min}$, and the burnout time is 
shortened from $7.55 \mathrm{~min}$ to $7.25 \mathrm{~min}$. Studies have shown that the presence of oxygen will reduce the force of the diffusion layer, and the increasing of air flow is done essentially to raise the oxygen quality [28]. As a result, an increase in air flow will result in a rapid reaction of oxygen with volatiles and fixed carbon, thereby facilitating the combustion of coal. In addition, the ignition temperature does not change with increased air flow, meaning that air flow has no effect on coal ignition characteristics.

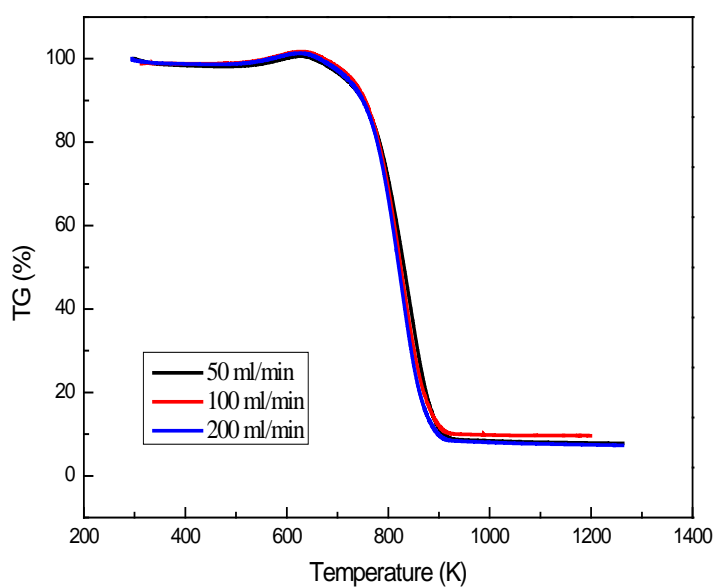

(a)

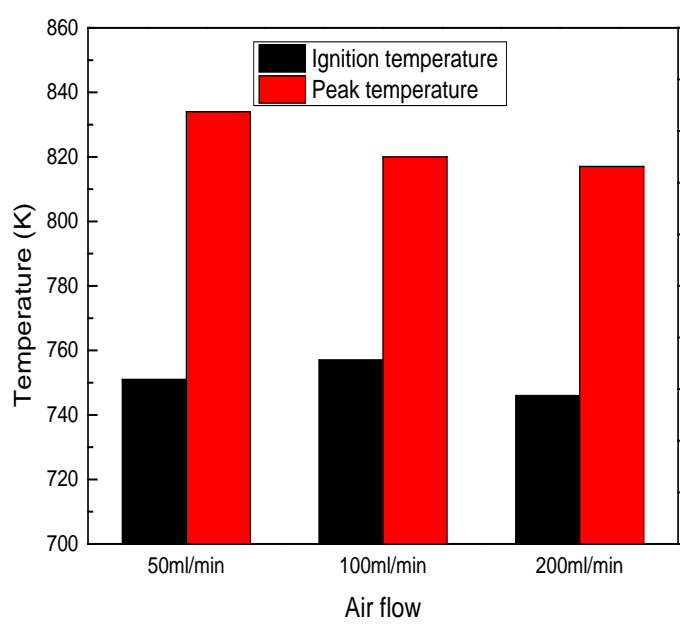

(c)

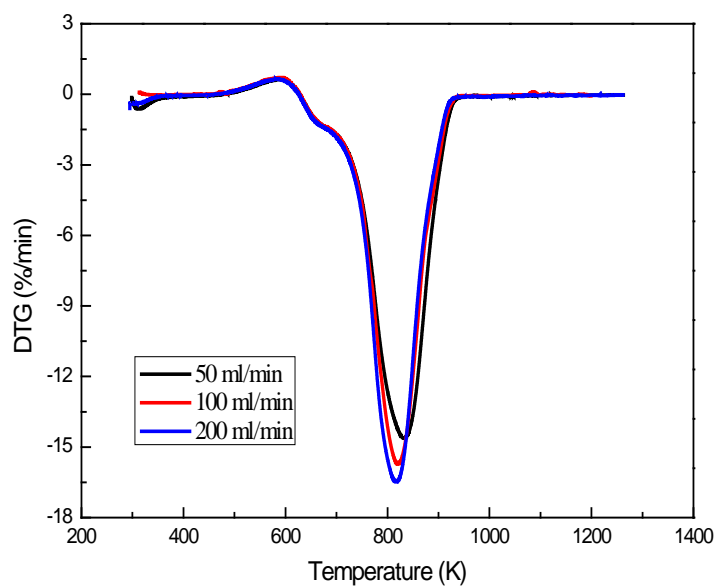

(b)

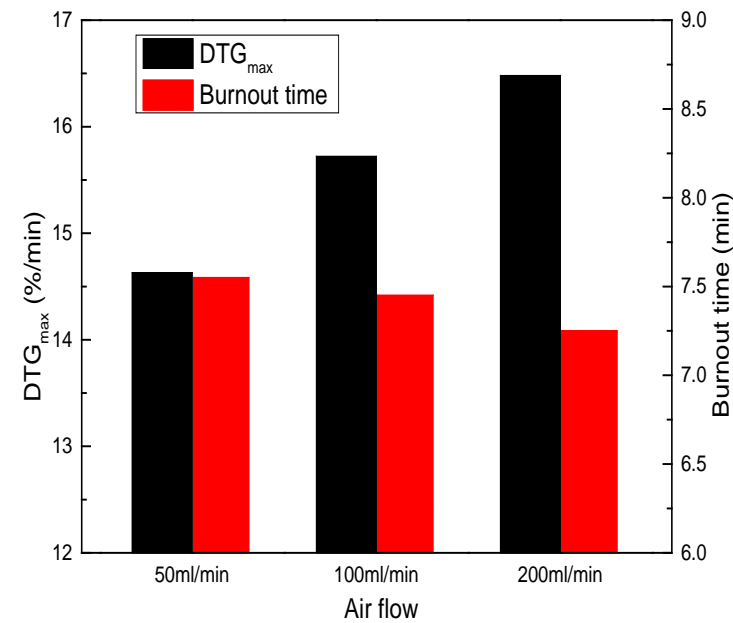

(d)

Figure 5. Effect of air flow on coal combustion: (a) TG profile; (b) DTG profile; (c) and (d) Coal combustion characteristics.

\subsubsection{Effect of Oxygen Content}

The combustion behavior of A coal under different oxygen contents are shown in Figure 6. The $10 \%, 20 \%$, and $30 \%$ oxygen contents reveal that the coal burns in a low oxygen atmosphere, an air atmosphere, and an oxygen-enriched atmosphere, respectively. Oxygen content greatly influences the combustion of coal. Coal combustion is weak under a low oxygen atmosphere, while it is significantly intensified under an oxygen-enriched atmosphere $\left(30 \% \mathrm{O}_{2}\right)$. The peak temperature is reduced from $906 \mathrm{~K}$ to $838 \mathrm{~K}, \mathrm{DTG}_{\max }$ is increased from $15.72 \% / \mathrm{min}$ to $18.86 \% / \mathrm{min}$, and burnout time is shortened from $7.45 \mathrm{~min}$ to $6.75 \mathrm{~min}$ when the oxygen content increased from $20 \%$ to $30 \%$. Moreover, ignition temperature is also affected by oxygen-enrichment, decreasing from $757 \mathrm{~K}$ to $703 \mathrm{~K}$. The presence of oxygen will reduce the force of the diffusion layer and oxygen-enrichment leads to faster reaction of fixed carbon and volatile material with oxygen to favorably enhance the combustion of coal [29]. The coal combustion process is easily regulated by oxygen content and can be obviously intensified by oxygen-enrichment. 


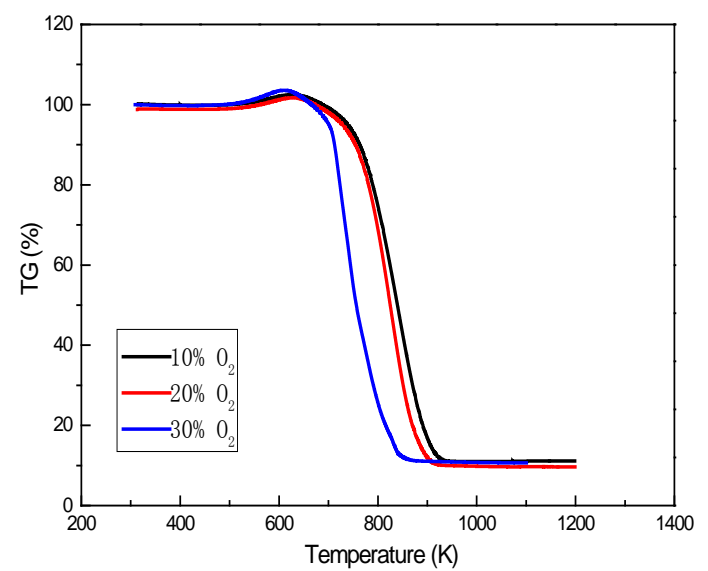

(a)

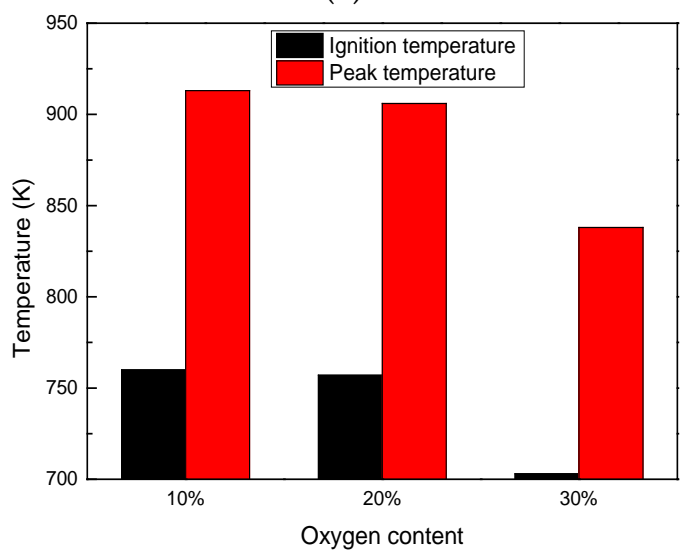

(c)

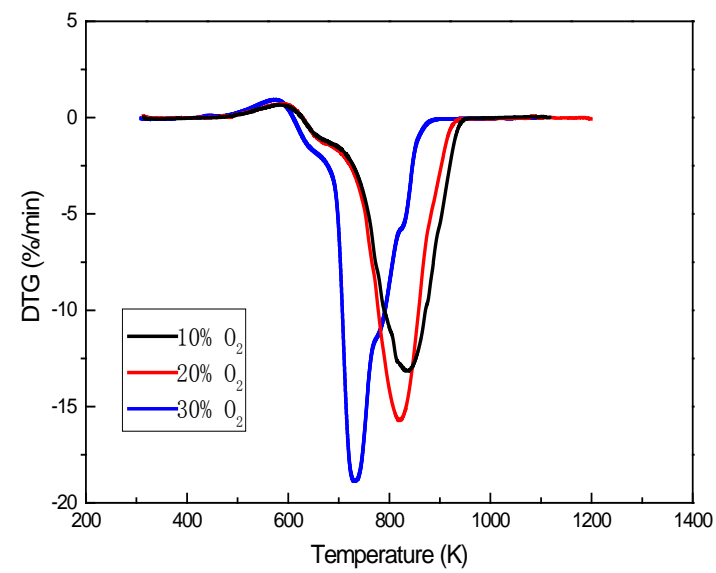

(b)

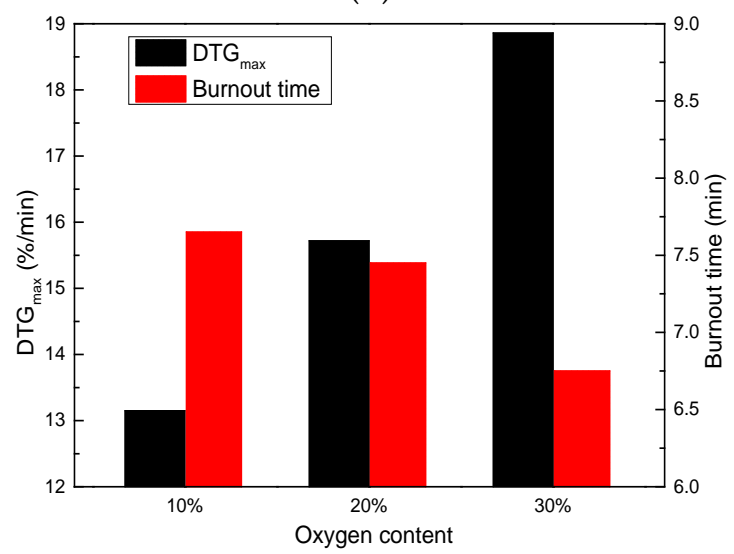

(d)

Figure 6. Effect of oxygen content on coal combustion: (a) TG profile; (b) DTG profile; (c) and (d) Coal combustion characteristics.

\subsubsection{Effect of Heating Rate}

Combustion behaviors of A coal under different heating rates are shown in Figure 7. Heating rate has a great influence on the combustion of the coal. The mass loss process is shorter when the heating rate is increased, revealing that a fast heating rate enhances coal combustion. Combustion intensity is also enhanced with the increase of air flow, which can be seen from the significant rising of the peak value and the reduction of the burnout time. The peak time (the time from ignition to maximum combustion) is shortened from $3.42 \mathrm{~min}$ to $3.03 \mathrm{~min}$, the $\mathrm{DTG}_{\max }$ is increased from $11.36 \% / \mathrm{min}$ to $16.16 \% / \mathrm{min}$, and the burnout time is shortened from $12.10 \mathrm{~min}$ to $5.13 \mathrm{~min}$, when the heating rate is increased from $10 \mathrm{~K} / \mathrm{min}$ to $30 \mathrm{~K} / \mathrm{min}$. Meanwhile, coal combustion is obviously enhanced when the heating rate is increased from $10 \mathrm{~K} / \mathrm{min}$ to $20 \mathrm{~K} / \mathrm{min}$. Coal combustion is further enhanced when the heating rate continuously increases to $30 \mathrm{~K} / \mathrm{min}$, but the enhanced degree is not a patch on the increase from $10 \mathrm{~K} / \mathrm{min}$ to $20 \mathrm{~K} / \mathrm{min}$. This means that coal combustion should take place with a suitable heating rate. In addition, the ignition temperature does not change with increased heating rates, indicating that the heating rate has no effect on coal ignition characteristics. 


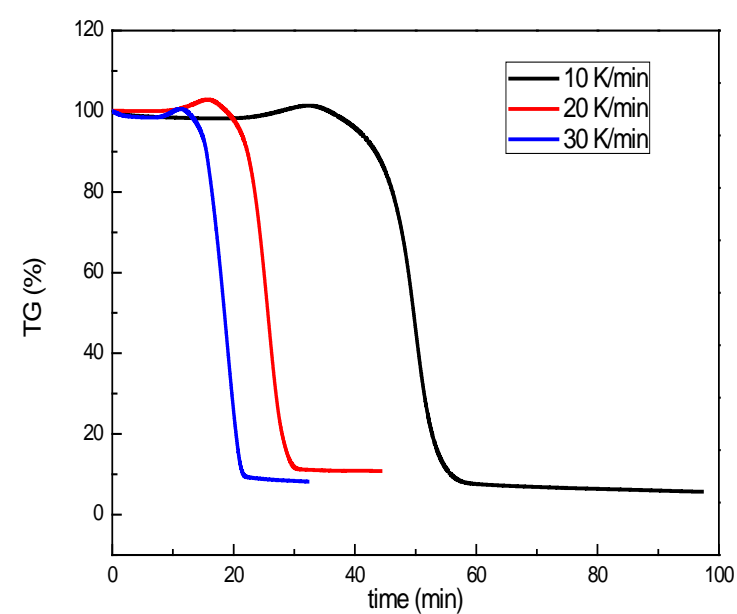

(a)

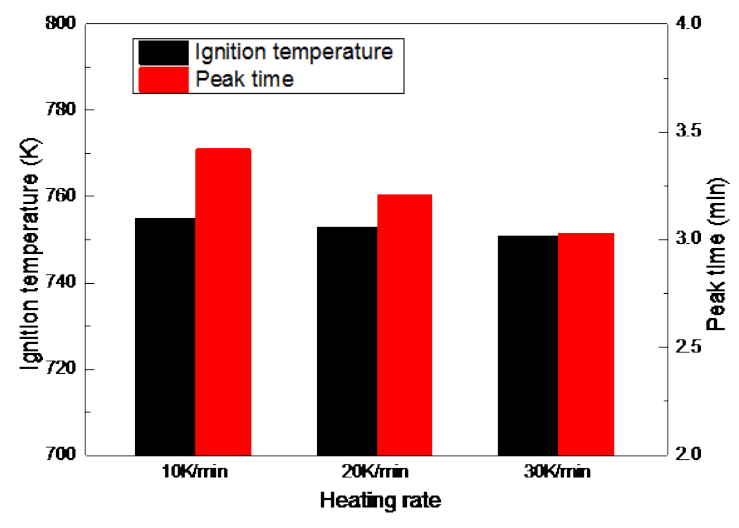

(c)

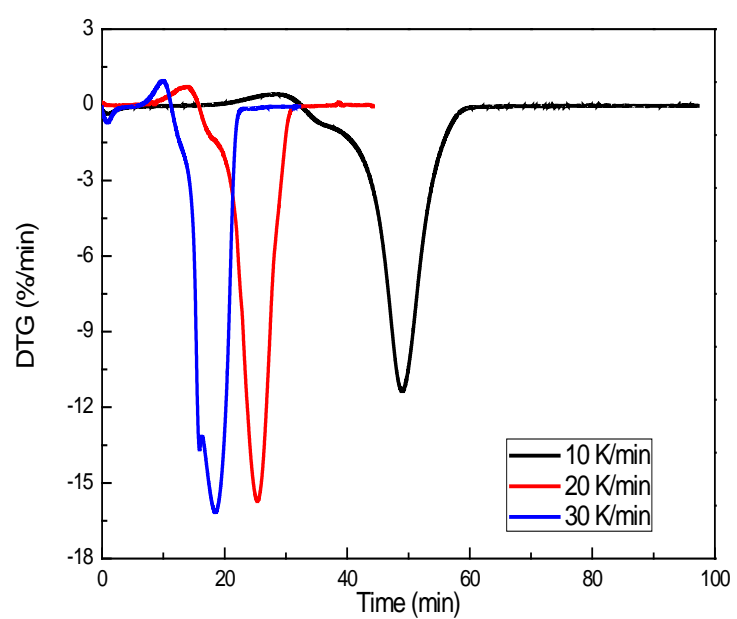

(b)

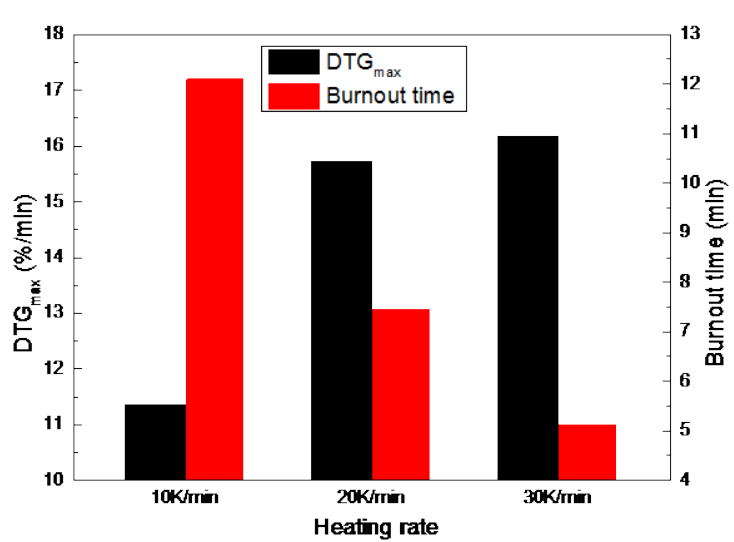

(d)

Figure 7. Effect of heating rate on coal combustion: (a) TG profile; (b) DTG profile; (c) and (d) Coal combustion characteristics.

\section{Conclusions}

The thermal behaviors of three coals and the effect of combustion parameters on their combustion behaviors were investigated with TGA. A summary of the results follows:

(1) Three coals have a similar trend of pyrolysis that occurs at about $670 \mathrm{~K}$ and this process continuously proceeds along with their combustion. The three coals also have comparable combustion behaviors of 745-761 K ignition temperature, 815-829 K peak temperature, $14.20-15.72 \% / \min \mathrm{DTG}_{\max }$, and $7.45-8.10$ min burnout time.

(2) Combustion kinetic parameters provide quantitative observation into coal combustion behavior. Low activation energy $\left(E_{\alpha}\right)$ and reaction order $(n)$ make coal, especially $C$ coal, have a simple combustion mechanism, great reactivity, easy ignition, and a low peak temperature in the combustion state.

(3) The suitable size for coal combustion in a kiln is that the content of less than $74 \mu \mathrm{m}$ is $60 \%$ to $80 \%$. Oxygen content and heating rate have a clear effect on coal combustion. Oxygen-enrichment and high heating rates can significantly enhance coal combustion, increase combustion intensity and peak value, and shorten burnout time.

Author Contributions: Qiang Zhong, Yongbin Yang, and Bin Xu conceived and designed the experiments; Qiang Zhong performed the experiments; Yongbin Yang and Bin Xu analyzed the data; Jian Zhang and Qian Li contributed reagents, materials, and analysis tools; Qiang Zhong and Jian Zhang wrote the paper; and Tao Jiang reviewed it before submission. 
Acknowledgments: This work is supported by the National Natural Science foundation of China (No. 51574284 and No. 51504293) and the Postdoctoral Science Foundation of Central South University.

Conflicts of Interest: The authors declare no conflict of interest.

\section{References}

1. Wang, S.; Guo, Y.F.; Chen, F.; He, Y.; Jiang, T.; Zheng, F.Q. Combustion reaction of pulverized coal on the deposit formation in the kiln for iron ore pellet production. Energy Fuels 2016, 30, 6123-6131. [CrossRef]

2. Mishra, S.; Roy, G.G. Effect of amount of carbon on the reduction efficiency of iron ore-coal composite pellets in multi-layer bed rotary hearth furnace (RHF). Metall. Mater. Trans. B 2016, 47, 2347-2356. [CrossRef]

3. Yang, Y.B.; Cui, L.N.; Li, X.S.; Li, Q.; Jiang, T.; Ge, J. Novel technology on preparation of double-layered pellets for sulfur and arsenic-bearing gold concentrates. J. Cent. South Univ. 2013, 20, 2967-2973. [CrossRef]

4. Zhu, D.Q.; Mendes, Y.; Chun, T.J.; Pan, J.; Li, Q.H.; Li, J.; Qiu, G.Z. Direct reduction behaviors of composite binder magnetite pellets in coal-based grate-rotary kiln process. ISIJ Int. 2011, 51, 214-219. [CrossRef]

5. Aziz, M.; Budianto, D.; Oda, T. Computational fluid dynamic analysis of co-firing of palm kernel shell and coal. Energies 2016, 9, 137. [CrossRef]

6. Folgueras, M.B.; Ramona, M.D.; Xiberta, J.; Prieto, I. Thermogravimetric analysis of the co-combustion of coal and sewage sludge. Fuel 2003, 82, 2051-2055. [CrossRef]

7. Sadrmezhaad, S.K.; Ferdowsi, A.; Payab, H. Mathematical model for a straight grate iron ore pellet induration process of industrial scale. Comp. Mater. Sci. 2008, 44, 296-297. [CrossRef]

8. Zhang, Y.Y.; Zhang, Z.Z.; Zhu, M.M.; Cheng, F.Q.; Zhang, D.K. Interactions of coal gangue and pine sawdust during combustion of their blends studied using differential thermogravimetric analysis. Bioresour. Technol. 2016, 214, 396-403. [CrossRef] [PubMed]

9. Jayaraman, K.; Kok, M.V.; Gokalp, I.P. Combustion and gasification studies of different sized coal particles using TGA-MS. Appl. Therm. Eng. 2017, 125, 1446-1455. [CrossRef]

10. Li, T.; Zhan, P.T.; Lei, M.; Li, Z.Z. Understanding hydrothermal dechlorination of PVC by focusing on the operating conditions and hydrochar characteristics. Appl. Sci. 2017, 7, 256-258. [CrossRef]

11. Font, R.; Fullana, A.; Conesa, J.A.; Llavador, F. Analysis of the pyrolysis and of diff combustion erent sewage sludges by TG. J. Anal. Appl. Pyrol. 2001, 58, 927-941. [CrossRef]

12. Chen, W.; Wang, F.; Kanhar, A.H. Sludge acts as a catalyst for coal during the co-combustion process investigated by thermogravimetric analysis. Energies 2017, 10, 1993. [CrossRef]

13. Holland, T.; Fletcher, T.H. Comprehensive model of single particle pulverized coal combustion extended to oxy-coal conditions. Energy Fuels 2017, 31, 2722-2739. [CrossRef]

14. Li, F.X.; Li, S.Z.; Chou, Y.Z. Thermal analysis study of the effect of coal-burning additives on the combustion of coals. J. Therm. Anal. Calorim. 2009, 95, 633-638.

15. Zhong, Q.; Yang, Y.B.; Jiang, T.; Li, Q.; Xu, B. Xylene activation of coal tar pitch binding characteristics for production of metallurgical quality briquettes from coke breeze. Fuel Process. Technol. 2016, 148, 12-18. [CrossRef]

16. Zhong, Q.; Yang, Y.B.; Li, Q.; Xu, B.; Jiang, T. Coal tar pitch and molasses blended binder for production of formed coal briquettes from high volatile coal. Fuel Process. Technol. 2017, 157, 12-19. [CrossRef]

17. Zhong, Q.; Yang, Y.B.; Li, Q.; Tao, J. Thermogravimetric analysis of coal used in rotary kiln of iron ore oxide pellet. In 7th International Symposium on High-Temperature Metallurgical Processing; Wiley: Nashville, TN, USA, 2016; pp. 351-358.

18. Zhong, Q.; Zhang, J.; Yang, Y.B.; Jiang, T.; Li, Q.; Xu, B. Combustion Behavior of Coals in Rotary Kiln and Their Interaction on Co-combustion. Energy Fuels 2018, 32, 3833-3841. [CrossRef]

19. Vyazovkin, S.; Burnham, A.K.; Criado, J.M.; Perez-maqueda, L.A.; Popescu, C.; Sbirrazzuoli, N. ICTAC kinetics committee recommendations for performing kinetic computations on thermal analysis data. Thermochim. Acta 2011, 520,1-19. [CrossRef]

20. Artemyeva, A.A.; Seames, W.S.; Pierce, D.T.; Kozliak, E.I. Molecular scale studies that inform trace element sulfide evaporation and atomization behavior during coal combustion. Fuel 2017, 188, 544-552. [CrossRef]

21. Saeed, M.A.; Andrews, G.E.; Phylaktou, H.N.; Gibbs, B.M. Global kinetics of the rate of volatile release from biomasses in comparison to coal. Fuel 2016, 181, 347-357. [CrossRef] 
22. Rubiera, A.; Pevida, F.C.; Pis, J.J. A comparison of different methods for predicting coal devolatilisation kinetics. J. Anal. Appl. Pyrol. 2001, 58, 685-701.

23. Chandrasekaran, A.; Ramachandran, S.; Subbiah, S. Determination of kinetic parameters in the pyrolysis operation and thermal behavior of Prosopis juliflora using thermogravimetric analysis. Bioresour. Technol. 2017, 233, 413-422. [CrossRef] [PubMed]

24. Mendez, A.; Fidalgo, J.M.; Guerrero, F.; Gasco, G. Characterization and pyrolysis behaviour of different paper mill waste materials. J. Anal. Appl. Pyrol. 2009, 86, 66-73. [CrossRef]

25. Liu, Z.J.; Hu, W.H.; Jiang, Z.H.; Mi, B.B.; Fei, B.H. Investigating combustion behaviors of bamboo, torrefied bamboo, coal and their respective blends by thermogravimetric analysis. Renew. Energy 2016, 87, 346-352. [CrossRef]

26. Dwaraoudi, S.; Devi, T.U.; Rao, S.M.; Ranjan, M. Influence of Pellet Size on Quality and Microstructure of Iron Ore Pellets. ISIJ Int. 2008, 48, 768-769. [CrossRef]

27. White, J.E.; Catallo, W.J.; Legendre, B.L. Biomass pyrolysis kinetics: A comparative critical review with relevant agricultural residue case studies. J. Anal. Appl. Pyrol. 2011, 91, 1-4. [CrossRef]

28. Wang, M.Y.; Liao, B.; Liu, Y.Q.; Wang, S.B.; Qing, S.; Zhang, A.M. Numerical simulation of oxy-coal combustion in a rotary cement kiln. Appl. Therm. Eng. 2016, 103, 491-500. [CrossRef]

29. Kim, G.M.; Kim, J.P.; Lisandy, K.Y.; Jeon, C.H. Experimental model development of oxygen-enriched combustion kinetics on porous coal char and non-porous graphite. Energies 2017, 10, 1436. [CrossRef]

(C) 2018 by the authors. Licensee MDPI, Basel, Switzerland. This article is an open access article distributed under the terms and conditions of the Creative Commons Attribution (CC BY) license (http://creativecommons.org/licenses/by/4.0/). 